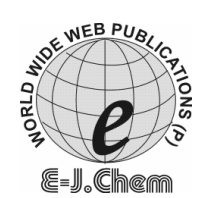

http://www.e-journals.net
ISSN: 0973-4945; CODEN ECJHAO

E-Journal of Chemistry

2008, 5(S1), 987-996

\title{
Synthesis and Application of Acid Dyes Based on 3-(4-Aminophenyl)-5-benzylidene-2-substituted phenyl-3, 5-dihydroimidazol-4-one
}

\author{
DEVANG N. WADIA and PRAVIN M. PATEL* \\ Industrial Chemistry Department, \\ V.P. \& R.P.T.P. Science College, \\ Vallabh Vidyanagar-388120.Anand, Gujarat. INDIA. \\ drpravinpatel@rediffmail.com;Tel: +919998321839
}

Received 11 March 2008; Accepted 10 May 2008

\begin{abstract}
A series of eight novel heterocyclic based monoazo acid dyes were synthesized using various substituted imidazol-4-one as diazo component and coupled with various amino-napthol sulphonic acids. The resultant dyes were characterized using standard spectroscopic methods and then dyeing performance on wool fabric was assessed. Final results concluded that exhaustion $(\% \mathrm{E})$ of the dyes on wool fibers increased with decreasing $\mathrm{pH}$ of application and that fixation $(\% \mathrm{~F})$ of the dyes on wool fibers increased with increasing $\mathrm{pH}$ of application and the highest total fixation efficiency was achieved at $\mathrm{pH}$ 5. Wash and light fastness properties of prepared dyes showed encouraging results.
\end{abstract}

Keywords: Imidazolone, Acid dyes, Wool, Exhaustion, Fixation.

\section{Introduction}

The past three decades have witnessed considerable innovation in the field of azo dye chemistry based on heterocyclic systems and studies in the synthesis of such derivatives have been reported ${ }^{1-5}$ Most of the recent research has focused on structural variations of existing types, for example variations in substituent, especially on the side chains of the coupling components. The use of heterocyclic coupling component and diazo components in the synthesis of azo dyes is well established, and the resultant dyes exhibit good tinctorial strength and brighter dyeing than those derived from aniline - based components. Most 
heterocyclic dyes of technical interest for application to textiles are derived from diazo components consisting of five-membered rings containing one sulphur heteroatom and to which a diazotisable amino group is directly attached. The ring may also possess one or more nitrogen heteroatom and be fused to another aromatic ring. These diazo components are capable of providing red to blue color dyes that meet the rigorous technical and economical requirements demanded of them by both manufacturer and user. Intensive efforts have been made in the investigation of monoazo dyes in which a heterocyclic system replaces one of the usual carboxylic systems. Many different heterocyclic diazo components have been studied, especially derivatives of thiazole, imidazole, benzimidazole owing to the marked bathochromic effect of such groups ${ }^{6-12}$

A majority of acid dyestuffs are sulphonic acid derivatives of azo dyes. The free dye acids are difficult to isolate and are hydroscopic in nature making it difficult to pack and store them. These dyes are invariably isolated as sodium salts. In the present paper, we report the synthesis, characterization, application and dyeing properties of some acid dyes derived from imidazolo-4-ones derivatives. However, no report including the use of an amino derivative of this heterocycle in the preparation of acid dyes is evident in the open literature.

\section{Experimental}

All the chemicals and solvents used were of laboratory grade and solvents were purified. Completion of the reaction was monitored by TLC using silica gel $\mathrm{GF}_{254}$ (E.Merck), and toluene:methanol as solvent $(8: 2)$. The final dyes were purified by column chromatography using silica gel in increasing percentage of ethyl acetate in carbon tetrachloride. IR (Infrared Spectrum) $\left(\mathrm{KBr}, \mathrm{cm}^{-1}\right)$ were recorded on a Shimadzu-8400 FT-IR spectrometer, ${ }^{1} \mathrm{H}$ PMR spectra on a Brucker spectrometer $(300 \mathrm{MHz})$ using TMS as a internal standard (chemical shift in $\delta$,ppm) in $\mathrm{CDCl}_{3}$ and $\mathrm{DMSOd}_{6}$ and C, H, N analysis on Perkin Elmer (U.S.A) 2400 Series. Wool fabrics and dyeing facilities was provided by ATUL Ltd. (India).

Preparation of 4-arylidene-2-phenyl-5-(4H)-oxazolones (a) 4-Arylidene-2-phenyl-5-(4H)-oxazolones were prepared according to the reported method ${ }^{13,14}$.

General procedure for the preparation of 3-(4-amino phenyl)-5-benzylidene-2substituted phenyl-3, 5-dihydro-imidazol-4-one (b)

Equimolar amount of 4-arylidene-2-phenyl-5-(4H)-oxazolone and $p$-phenylene diamine were taken in a reaction flask attached with a reflux condenser and kept under reflux for $6 \mathrm{~h}$, with dry pyridine as solvent. The content of the reaction mixture was poured in ice-water medium to give colored precipitates. The completion of reaction was monitored by TLC using toluene:methanol (8:2). Yield $62-70 \%$. The product was crystallised from ethyl alcohol. ( Scheme 1).

Preparation of 3-(4-amino-phenyl)-5-(4-methoxybenzylidene-2-phenyl-3, 5-dihydroimidazol-4-one) (b).

Equimolar amount of 4-methoxy benzylidene-2-phenyl-5-(4H)-oxazolones and $p$-phenylene diamine were taken in a reaction flask attached with a reflux condenser and kept under reflux for $6 \mathrm{~h}$ with dry pyridine as solvent. The content of the reaction mixture was poured in ice-water medium to give colored precipitates. The completion of reaction was monitored by TLC using toluene:methanol $(8: 2)$. The product was crystallised from ethyl alcohol ${ }^{14}$ (Scheme 1). 


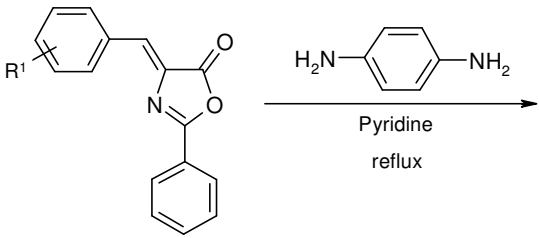

(a)

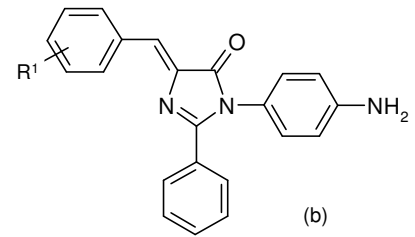

i) Diazotization

ii) Coupling

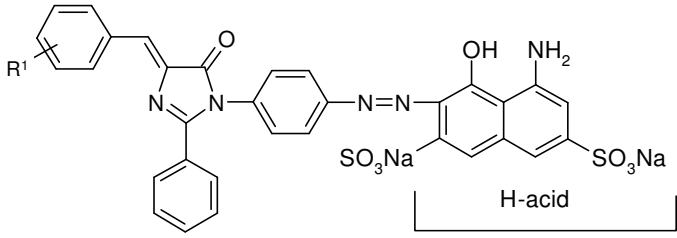

(c)

$\mathrm{R}^{2}$

\begin{tabular}{ccc}
\hline Dyes & $\mathrm{R}^{1}$ & $\mathrm{R}^{2}$ \\
\hline D1 & $4-\mathrm{OCH}_{3}$ & $(\gamma)$-Acid \\
D2 & $4-\mathrm{OCH}_{3}$ & $(\mathrm{~J})$-Acid \\
D3 & $4-\mathrm{OCH}_{3}$ & $(\mathrm{H})$-Acid \\
D4 & $4-\mathrm{OCH}_{3}$ & $(\mathrm{R})$-Acid \\
D5 & $3,4,5-\mathrm{OCH}_{3}$ & $(\gamma)$-Acid \\
D6 & $3,4,5-\mathrm{OCH}_{3}$ & $(\mathrm{~J})$-Acid \\
D7 & $3,4,5-\mathrm{OCH}_{3}$ & $(\mathrm{H})$-Acid \\
D8 & $3,4,5-\mathrm{OCH}_{3}$ & $(\mathrm{R})$-Acid \\
\hline
\end{tabular}

Scheme 1. Synthesis of imidazolone based dyes D1 - D8

\section{IR Data}

3300-3270 ( $\left.\mathrm{cm}^{-1}\right)(-\mathrm{NH}), 3100-3010$ (Aromatic C-H), 1611 (C=C stretch), 1690 (C=O, imidazolinone ring), 1274 (C-O-C asymmetric stretch), 1026 (C-O-C symmetric stretch). Shown in Figure 1.

\section{${ }^{1}$ H NMR Data}

$(\delta, \mathrm{ppm}), \delta$ 8.04-6.60 (m, 13H, Ar-H), $\delta 6.01(\mathrm{~s}, 1 \mathrm{H}, \mathrm{Ph}-\mathrm{C}=\mathrm{CH}), \delta 4.63$ (br, 2H, $\left.-\mathrm{NH}_{2}\right), \delta$ $3.78\left(\mathrm{~s}, 3 \mathrm{H},-\mathrm{OCH}_{3}\right)$ [14]. Shown in Figure 2.

Diazotization of 3-(4-amino-phenyl)-5-(4-methoxybenzylidene-2-phenyl-3,5dihydro-imidazol-4-one) (b) and coupling with 1-napthol-8-amino-3,6-disulphonic acid $[H-A c i d](c)$

To the $25 \mathrm{~mL}$ of water in a beaker $2.96 \mathrm{~g}$ (95\% $0.01 \mathrm{~mole})$ of 3-(4-amino-phenyl)-5-(4methoxybenzylidene-2-phenyl-3, 5-dihydro-imidazol-4-one) was added. While stirring the suspension was cooled down to $5^{\circ} \mathrm{C}$ using ice. To this solution $3.67 \mathrm{~mL}$ ( $3 \mathrm{~N}, 0.011$ moles) of $\mathrm{NaNO}_{2}$ and $5 \mathrm{~g}$ of ice were added. Then, $2.6 \mathrm{~mL}$ of conc. $\mathrm{HCl}$ was added to obtain a diazo component of 3-(4-amino-phenyl)-5-(4-methoxybenzylidene-2-phenyl-3, 5-dihydroimidazol-4-one). Completion of diazotization reaction was checked by starch iodide test. Excess $\mathrm{HNO}_{2}$ was removed by adding a small amount of sulfamic acid. 


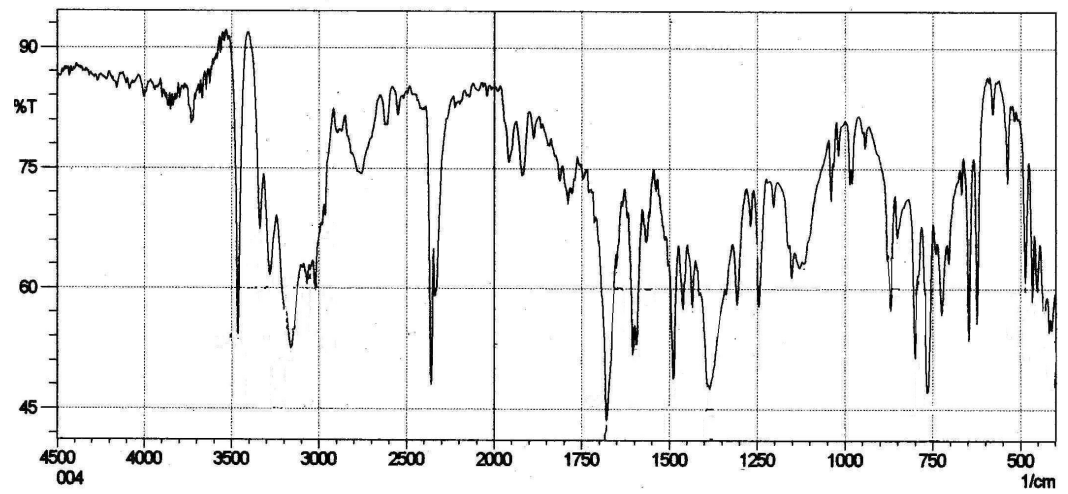

Figure 1 Infrared spectra of 3-(4-amino phenyl)-5-(4-methoxybenzylidene-2-phenyl-3, 5dihydro-imidazol-4-one) (b)

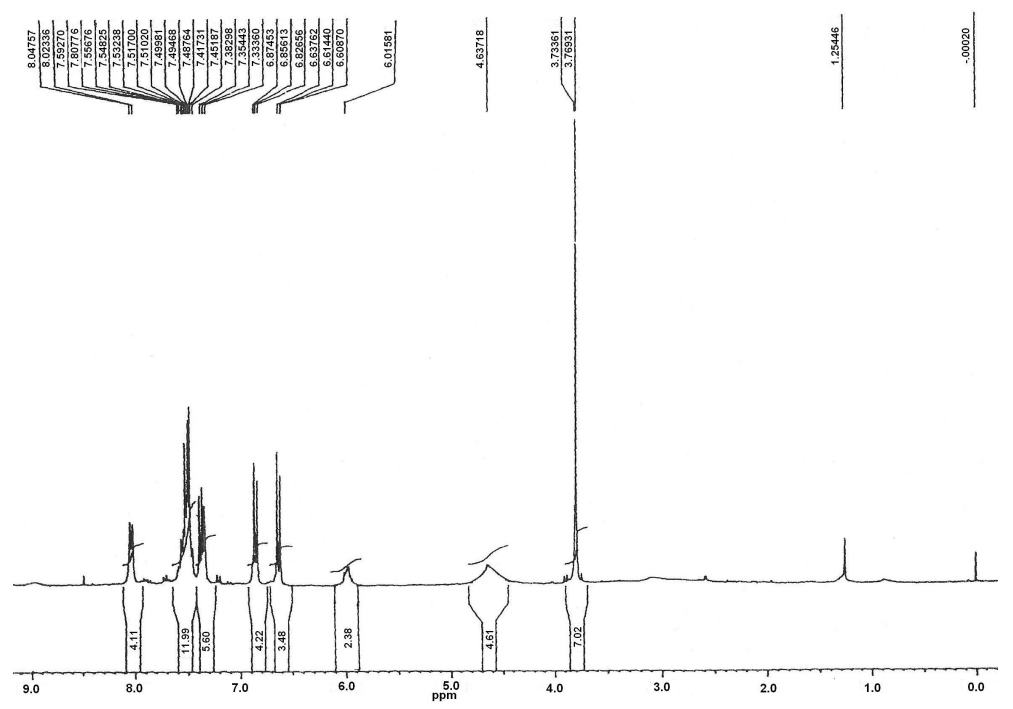

Figure 2. NMR spectra of 3-(4-amino phenyl)-5-(4-methoxybenzylidene-2-phenyl-3, 5dihydro-imidazol-4-one) (b)

To another beaker $3.9 \mathrm{~g}(82 \%, 0.01$ mole) of 1-napthol-8-amino-3, 6-disulphonic acid (H-Acid) and $40 \mathrm{~mL}$ of water was added and the $\mathrm{pH}$ was adjusted between 9-10, using $10 \%$ $\mathrm{Na}_{2} \mathrm{CO}_{3}$. Into this aqueous solution, the above prepared diazo solution was added dropwise using dropping funnel while keeping the temperature $0-5^{0} \mathrm{C}$ to complete the coupling reaction. The progress of the reaction was monitored by thin layer chromatography (TLC) using a DMF:water mixture (5:2 by volume) as developing solvent and silica gel TLC plates as the stationary phase. Final dye is purified by column chromatography ${ }^{15}$ (Scheme 1).

\section{IR Data}

$\left(\mathrm{cm}^{-1}\right) 1581 \quad \mathrm{~N}=\mathrm{N}(\mathrm{S}), 1128 \quad \mathrm{~S}=\mathrm{O}(\mathrm{S}), 3500 \quad \mathrm{~N}-\mathrm{H}(\mathrm{S}), 3435 \quad \mathrm{OH}, 1700 \quad \mathrm{C}=\mathrm{O}(\mathrm{S})$ Imidazolinone ring, 3000 (Aromatic $\mathrm{C}-\mathrm{H}$ s), 1600-1500 $\mathrm{C}=\mathrm{C}(\mathrm{s})$, below $900 \mathrm{C}$ $\mathrm{H}(\mathrm{B}), 1900-1500 \mathrm{C}=\mathrm{N}$ (s), 1226 (C-O-C asymmetric stretch), 1045 (C-O-C symmetric stretch). Shown in Figure 3. 


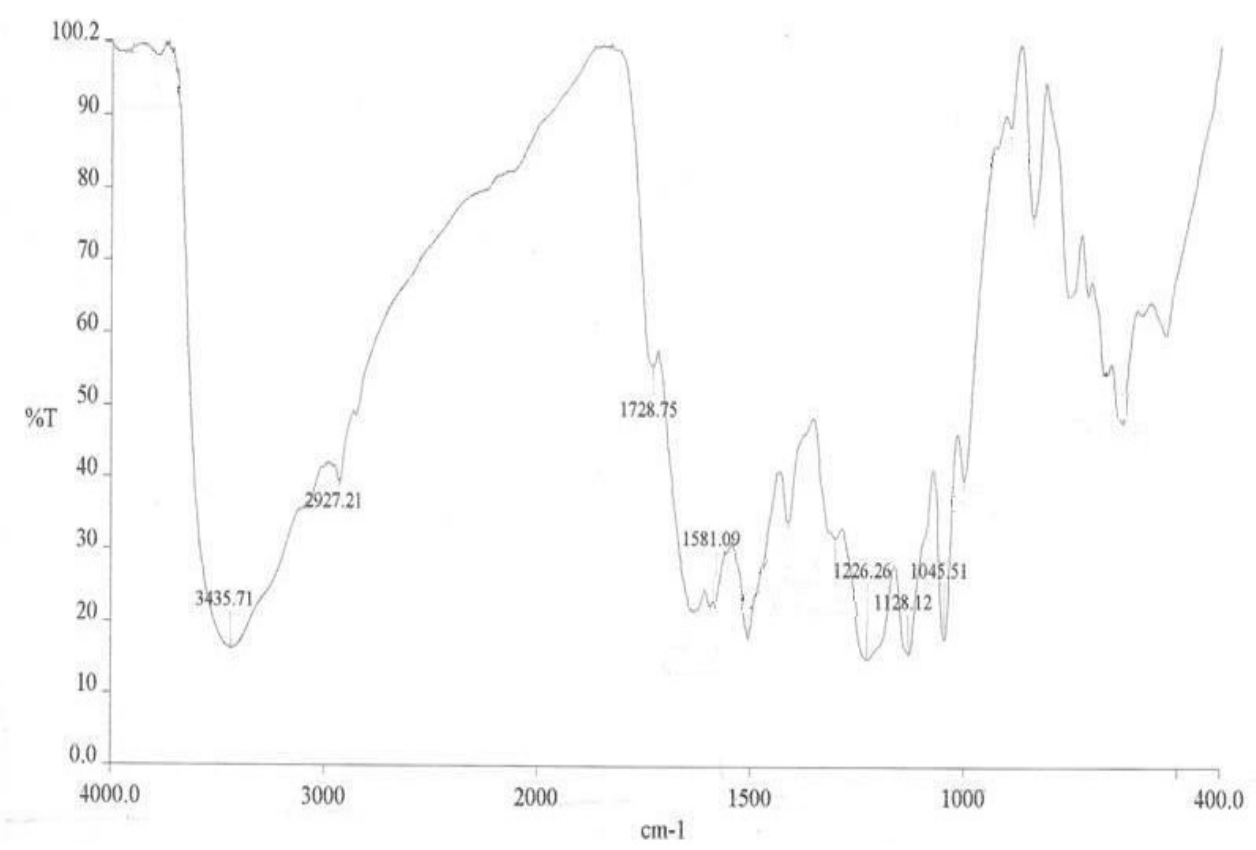

\section{${ }^{1}$ H NMR Data}

Figure 3. Infrared Spectra of final compound (C)

$(\delta, \mathrm{ppm}) \delta 7.592-6.608(\mathrm{~m}, 16 \mathrm{H}, \mathrm{Ar}-\mathrm{H}), \delta 5.850(\mathrm{~s}, 1 \mathrm{H},-\mathrm{OH}), \delta 4.637\left(\mathrm{~s}, 2 \mathrm{H},-\mathrm{NH}_{2}\right), \delta 3.799-$ $3.789\left(\mathrm{~s}, 3 \mathrm{H},-\mathrm{OCH}_{3}\right)$. Shown in Figure 4.

\section{General procedure for dyeing}

Knitted wool, was initially treated in an aqueous solution with a liquor ratio 50:1 containing $0.5 \mathrm{~g} / \mathrm{l}$ sodium carbonate and $2 \mathrm{~g} / \mathrm{L}$ non-ionic detergent at $60^{\circ} \mathrm{C}$ for $30 \mathrm{~min}$, after which time it was thoroughly rinsed and dried at room temperature.

$\begin{array}{ll}\text { Application of acid dyes } & \text { on wool in } 2 \% \text { shade } \\ \text { Weight of material } & : 2 \mathrm{~g} \text { (wool) } \\ \text { Weight of dye } & : 40 \mathrm{mg} \\ \text { MLR ratio } & : 1: 30 \\ \text { Acetic acid added } & : 2-3 \mathrm{~mL} \\ \text { pH of dye bath } & : 4.5-5 \\ \text { Temperature } & : 95-100^{\circ} \mathrm{C} \\ \text { Total Volume } & : 160 \mathrm{~mL}\end{array}$

The dye bath was prepared by dissolving $40 \mathrm{mg}$ heterocyclic acid azo dyes in distilled water (160 mL.). The $\mathrm{pH}$ of the solution was adjusted to 4.5-5 with acetic acid 3-4 mL. Dyeing was carried out in sealed, stainless steel dye pots. The temperature of dye bath was first raised to $50^{\circ} \mathrm{C}$ and the fabric for dyeing (wool) was slowly introduced into the dye bath. The temperature of dye bath then raised to $95-100^{\circ} \mathrm{C}$ and dyeing was continued for an hour. The dye liquor was decanted in to $250-\mathrm{mL}$. volumetric flask. The dyed material was washed several times with distilled water and the washings were collected in the same volumetric flask consisting of dye bath liquor. Finally the solution was diluted to $250 \mathrm{~mL}$ and used for exhaustion study. The dyed pattern was squeezed and dried. Dyeing was carried out in sealed, stainless steel dye pots of $120 \mathrm{~cm}^{3}$ capacity in a laboratory-scale dyeing machine (ACE- 6000T $)^{16}$. 


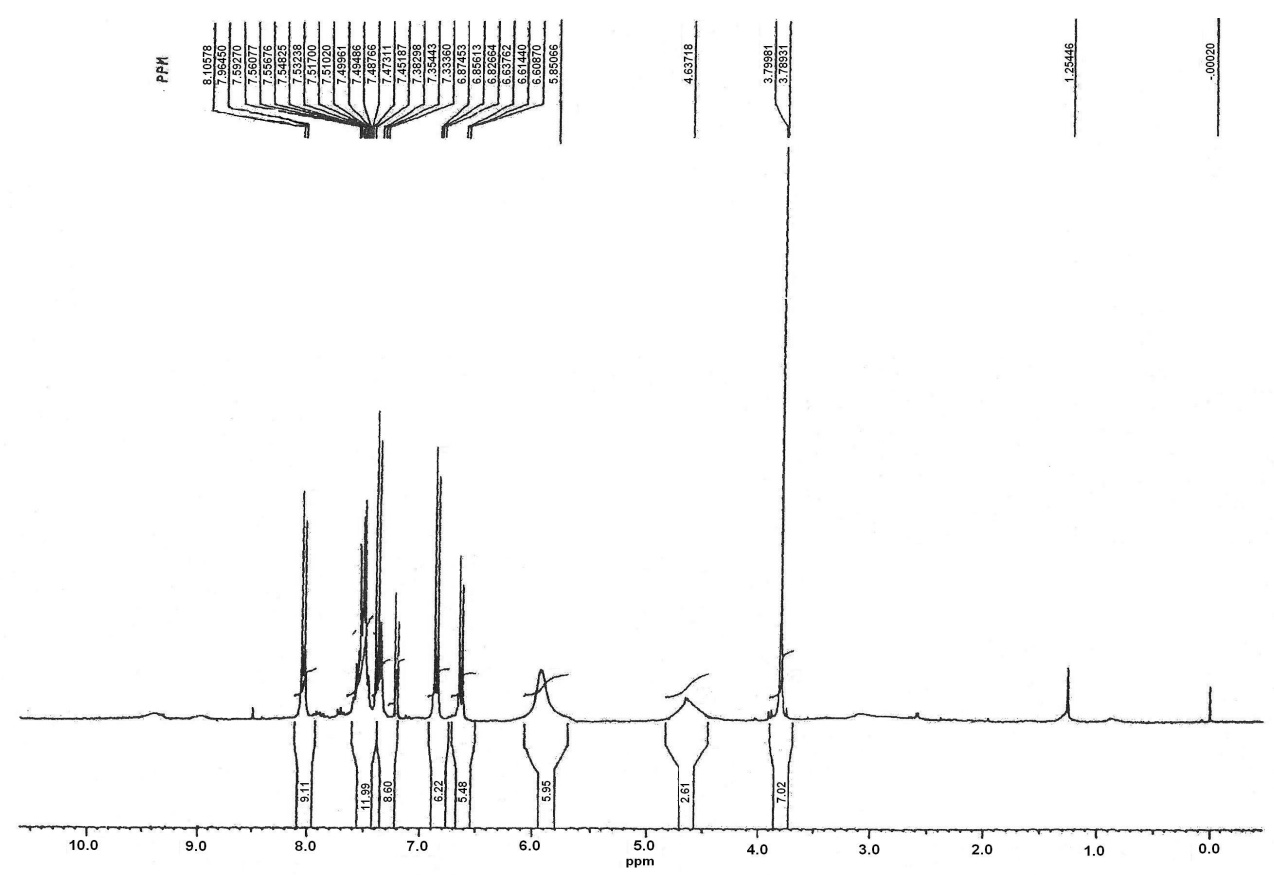

Figure 4. NMR Spectra of final compound (C).

Determination of exhaustion (\%E) and fixation (\%F)

To determine dyeing characteristics, absorbance measurements of the original dyebath and the exhausted dyebath were carried out using a Shimadzu UV-2401PC UV/visible spectrophotometer. Using a previously established absorbance/ concentration relationship at the $\lambda \max$ of the dyes, the quantity of acid dye in solution was calculated and the extent of exhaustion $(\% \mathrm{E})$ achieved was determined using following Equation, where $\mathrm{D}_{0}$ and $\mathrm{D}_{t}$ are the quantities of dye initially in the bath and of residual dye in the final bath, respectively (Table 1$)^{17}$.

Table 1. Exhaustion and fixation study of dyes D1-D8 (Wool).

\begin{tabular}{ccccccc}
\hline Dye & Dye Designation & $\begin{array}{c}\text { Amt. of } \\
\text { dye left in } \\
\text { dye bath a } \\
\text { mg }\end{array}$ & $\begin{array}{c}\text { Amt. of dye } \\
\text { Exhausted } \\
\text { from dye bath } \\
\text { b=(40-a) mg. }\end{array}$ & $\begin{array}{c}\% \\
\text { exhaustion } \\
\text { of dye } \frac{100 \times b}{40}\end{array}$ & $\begin{array}{c}\text { Amount of dye } \\
\text { present on dyed } \\
\text { pattern C mg. }\end{array}$ & $\begin{array}{c}\% \\
\text { fixation } \\
\text { dye }\end{array}$ \\
\hline D1 & $4-\mathrm{OCH}_{3},(\gamma)$ Acid & 15 & 25 & 62.5 & 20.11 & 80.44 \\
D2 & $4-\mathrm{OCH}_{3},(\mathrm{~J})$ Acid & 17.62 & 22.37 & 55.93 & 17.44 & 77.96 \\
D3 & $4-\mathrm{OCH}_{3},(\mathrm{H})$ Acid & 19.75 & 20.25 & 50.61 & 14.26 & 70.41 \\
D4 & $4-\mathrm{OCH}_{3},(\mathrm{R})$ Acid & 12.5 & 27.5 & 68.75 & 22.52 & 81.89 \\
D5 & $3,4,5-\mathrm{OCH}_{3},(\gamma)$ Acid & 13.87 & 26.12 & 65.31 & 21.94 & 83.99 \\
D6 & $3,4,5-\mathrm{OCH}_{3},(\mathrm{~J})$ Acid & 12.87 & 27.12 & 67.81 & 23.19 & 85.50 \\
D7 & $3,4,5-\mathrm{OCH}_{3},(\mathrm{H})$ Acid & 10.45 & 29.55 & 73.87 & 22.34 & 75.60 \\
D8 & $3,4,5-\mathrm{OCH}_{3},(\mathrm{R})$ Acid & 9.39 & 30.61 & 76.52 & 23.60 & 77.098 \\
\hline
\end{tabular}

$$
\% \mathrm{E}=\frac{\left(\mathrm{D}_{0}-\mathrm{D}_{\mathrm{t}}\right)}{\mathrm{D}_{0}} \times 100
$$


The extent of fixation $(\% \mathrm{~F})$ was calculated using Eqs. (2), where $\mathrm{D}_{\mathrm{e}}$ is the amount of extracted dye

$$
\% \mathrm{~F}=\frac{\left(\mathrm{D}_{0}-\mathrm{D}_{\mathrm{t}}-\mathrm{D}_{\mathrm{e}}\right)}{\mathrm{D}_{0}-\mathrm{D}_{\mathrm{t}}} \times 100
$$

\section{Fastness measurements}

Fastness to washing was assessed by the standard ISO CO6 C2S method test. A 10 X $4 \mathrm{~cm}$ dyed fabric strip stitched through the short end to SDC's multifibre test fabric was used. The washing was conducted on a Roaches washtec-P at $60^{\circ} \mathrm{C}$ for $30 \mathrm{~min}$, rinsed with cold water, air dried and analysed. Fastness to light was measured using a Xenotest 150S apparatus (Heraus Hanau). The results are shown in Table 2.

Table 2. Shades and fastness properties of dyes D1-D8

\begin{tabular}{cccc}
\hline Dyes & Color of dyes fabrics & Light fastness & Wash fastness \\
\hline D1 & Light Red & $4-5$ & 5 \\
D2 & Brown & 5 & 5 \\
D3 & Purple & 5 & $4-5$ \\
D4 & Orange & 5 & 4 \\
D5 & Light Red & $4-5$ & 5 \\
D6 & Brown & 5 & $4-5$ \\
D7 & Purple & 5 & 5 \\
D8 & Orange & 5 & $4-5$ \\
\hline
\end{tabular}

\section{Results and Discussion}

\section{Synthesis}

Compound (a) 4-Arylidene-2-phenyl-5-(4H)-oxazolones derivatives were prepared by Erlenmeyer condensation of benzolyglycine with different aldehydes in presence of sodium acetate and acetic anhydride ${ }^{13,14}$.

The prepared 5-oxazolone were treated with p-phenylene diamine in basic medium to prepared 3-(4-amino phenyl)-5-benzylidene-2-substituted phenyl-3, 5-dihydro-imidazol-4one (b). The IR Spectrum of compound (b) showed the NH bands at $3300-3270 \mathrm{~cm}^{-1}$, and the $\mathrm{C}=\mathrm{O}$ band nearly at $1690 \mathrm{~cm}^{-1}$ (Figure 1 )

The ${ }^{1} \mathrm{H}$ NMR spectrum shows broad peak at $4.63 \mathrm{ppm}$ was due to the protons of the $\mathrm{NH}_{2}$ group. The benzylidene proton of $(\mathrm{Ph}-\mathrm{C}=\mathrm{CH})$ was found in downfield region at $\delta 6.01$ ppm. In the case of $4-\mathrm{OCH}_{3}$, singlet is observed at $\delta 3.73 \mathrm{ppm}$ which corresponds to the three protons of $-\mathrm{OCH}_{3}$.(Figure 2).

3-(4-Amino-phenyl)-5-(4-methoxybenzylidene-2-phenyl-3, 5-dihydro-imidazol-4-one) (b) was diazotized and coupled with various substituted napthol mono and di-sulphonic acids with known reported methods to prepare compound (c) ${ }^{15}$.The IR Spectrum of compound (c) showed the $\mathrm{N}=\mathrm{N}$ bands at $1581 \mathrm{~cm}^{-1}, \mathrm{~N}-\mathrm{H}$ bands at $3500 \mathrm{~cm}^{-1},-\mathrm{OH}$ band at $3435 \mathrm{~cm}^{-1}$ and $\mathrm{C}=\mathrm{O}(\mathrm{S})$ Imidazolinone ring bands at $1700 \mathrm{~cm}^{-1}$. (Figure 3).

The ${ }^{1} \mathrm{H}$ NMR spectrum showed a multiplet at $\delta$ 7.592-6.608 ppm due to aromatic protons $(16 \mathrm{H})$, the benzylidene proton of $(\mathrm{Ph}-\mathrm{C}=\mathrm{CH})$ was also found in the same region but was over lapped by multiplet of aromatic protons. The spectrum showed a singlet at $\delta 4.637 \mathrm{ppm}$ due to the protons of $-\mathrm{NH}_{2}$ group. The spectrum showed a singlet at $\delta 5.850 \mathrm{ppm}$ due to the protons of $-\mathrm{OH}$ group. The position of protons of $-\mathrm{NH}_{2}$ and $-\mathrm{OH}$ groups depends upon the intramolecular hydrogen bonding into the sample tube. In the case of $4-\mathrm{OCH}_{3}$, singlet is observed at $\delta 3.799-3.789 \mathrm{ppm}$ which corresponds to the three protons of $-\mathrm{OCH}_{3}$. (Figure 4). 


\section{Visible spectral study}

The $\lambda_{\max }$ value of acid dyes of $\mathrm{H}$-acid, R-acid are higher than that of J-acid and $\gamma$-acid due to the presence of two sulphonic acid group providing the resonance structure in ethanol..

The $\lambda_{\max }$ value for a acid dye based on $\mathrm{H}$-acid, R-acid has shown bathochromic effect as compared to that of acid dye based on J-acid and $\gamma$-acid , this is applicable on the basis of presence of a second auxochromic group causing higher electron density in a diazonium component of the acid dye.

The $\lambda_{\max }$ values for acid dyes based on J-acid and $\gamma$-acid have shown hypsochromic effect as compared to that of a dye based on H-acid, R-acid This may be due to steric hindrance of the sulphonic acid group, ortho to azo group of the dye. Results are shown in Table 3.

\section{Dyeing properties}

In this context, the aim was to determine the level of fastness, displayed by prepared heterocyclic acid dyes on wool substrates.

The dyes were applied to wool at a $2 \%$ shade. \% Exhaustion and \%Fixation values are shown in Table 1. The hues and data on dye fastness properties are shown in Table 2 and $\lambda \max , E \max$ values are shown in Table 3 . The results showed that dyes D1-D8 had reasonably good wash and light fastness properties.

\section{Effect of $p H$ on exhaustion (\%E), fixation (\%F)}

The results in Figures 5 and 6 show that exhaustion $(\% \mathrm{E})$ of the dyes on wool fibers increased with decreasing $\mathrm{pH}$ of application and that fixation $(\% \mathrm{~F})$ of the dyes on wool fibers increased with increasing $\mathrm{pH}$ of application. Results displays that the highest total fixation efficiency was achieved at $\mathrm{pH} 5$.

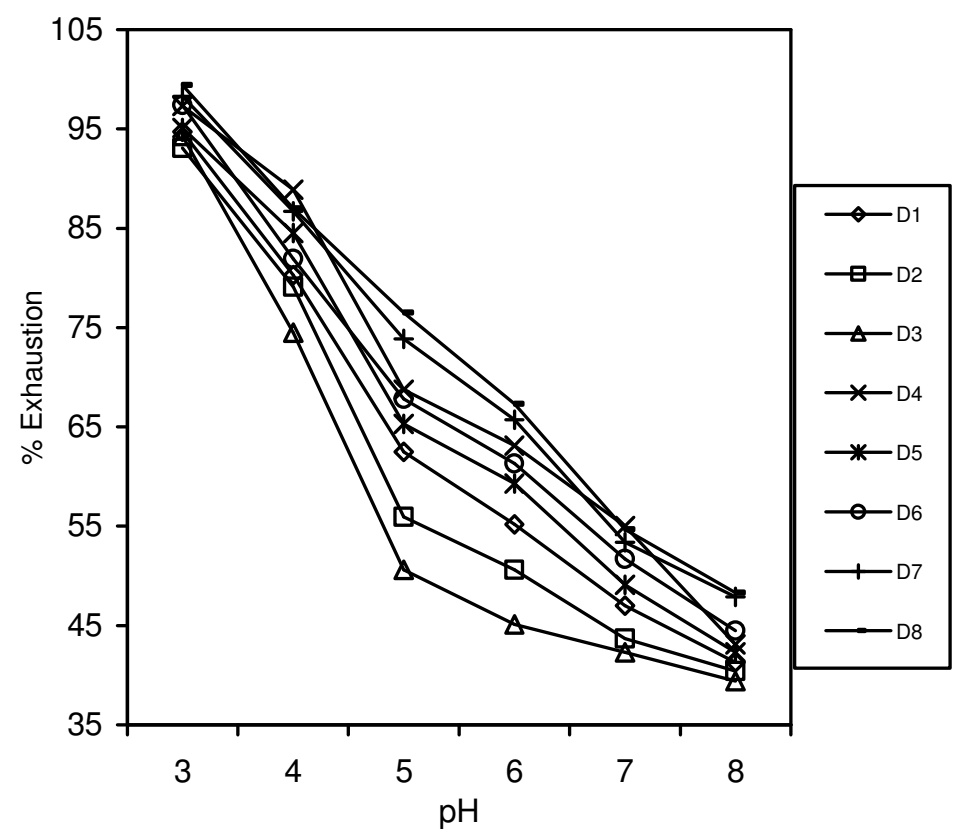

Figure 5. Effect of application $\mathrm{pH}$ on exhaustion (\%E). 
Table 3. Characterization of dyes D1-D8.

\begin{tabular}{|c|c|c|c|c|c|c|c|c|c|c|c|c|c|}
\hline \multirow{2}{*}{ Dye } & \multirow{2}{*}{ R1 } & \multirow{2}{*}{ R2 } & \multirow{2}{*}{$\begin{array}{l}\text { Molecular } \\
\text { formula }\end{array}$} & \multirow{2}{*}{$\begin{array}{l}\text { Mole Wt. } \\
\text { g/mol }\end{array}$} & \multirow{2}{*}{$\begin{array}{c}\text { Yield } \\
\%\end{array}$} & \multirow{2}{*}{$\begin{array}{c}\lambda \max n m \\
\text { Et-OH }\end{array}$} & \multirow{2}{*}{$\begin{array}{c}E \max \\
\mathrm{dm}^{3} \mathrm{~mol}^{-1} \\
\mathrm{~cm}^{-1}\end{array}$} & \multicolumn{3}{|c|}{ Found } & \multicolumn{3}{|c|}{ Calculated } \\
\hline & & & & & & & & $\mathrm{C}$ & $\mathrm{H}$ & $\mathrm{N}$ & $\mathrm{C}$ & $\mathrm{H}$ & $\mathrm{N}$ \\
\hline D1 & $4-\mathrm{OCH}_{3}$ & 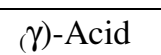 & $\mathrm{C}_{35} \mathrm{H}_{25} \mathrm{~N}_{5} \mathrm{O}_{6} \mathrm{~S}$ & 619.15 & 63 & 390 & 56,485 & 63.73 & 4.12 & 11.13 & 63.96 & 4.07 & 11.03 \\
\hline D2 & $4-\mathrm{OCH}_{3}$ & (J) -Acid & $\mathrm{C}_{33} \mathrm{H}_{25} \mathrm{~N}_{5} \mathrm{O}_{6} \mathrm{~S}$ & 619.15 & 65 & 405 & 59,414 & 63.71 & 4.11 & 11.12 & 63.96 & 4.07 & 11.03 \\
\hline D3 & $4-\mathrm{OCH}_{3}$ & (H) -Acid & $\mathrm{C}_{33} \mathrm{H}_{25} \mathrm{~N}_{5} \mathrm{O}_{9} \mathrm{~S}_{2}$ & 699.71 & 65 & 550 & 54,550 & 56.54 & 3.57 & 09.89 & 56.65 & 3.60 & 10.01 \\
\hline D4 & $4-\mathrm{OCH}_{3}$ & (R) -Acid & $\mathrm{C}_{33} \mathrm{H}_{24} \mathrm{~N}_{4} \mathrm{O}_{9} \mathrm{~S}_{2}$ & 684.10 & 65 & 490 & 48,815 & 57.63 & 3.44 & 8.02 & 57.89 & 3.53 & 8.18 \\
\hline D5 & $3,4,5-\mathrm{OCH}_{3}$ & $(\gamma)$-Acid & $\mathrm{C}_{35} \mathrm{H}_{29} \mathrm{~N}_{5} \mathrm{O}_{8} \mathrm{~S}$ & 679.17 & 62 & 445 & 48,630 & 61.69 & 4.32 & 10.32 & 61.85 & 4.30 & 10.30 \\
\hline D6 & $3,4,5-\mathrm{OCH}_{3}$ & (J) -Acid & $\mathrm{C}_{35} \mathrm{H}_{29} \mathrm{~N}_{5} \mathrm{O}_{8} \mathrm{~S}$ & 679.17 & 55 & 452 & 55,142 & 61.72 & 4.33 & 10.23 & 61.85 & 4.30 & 10.30 \\
\hline D7 & $3,4,5-\mathrm{OCH}_{3}$ & (H) -Acid & $\mathrm{C}_{35} \mathrm{H}_{29} \mathrm{~N}_{5} \mathrm{O}_{11} \mathrm{~S}_{2}$ & 759.71 & 70 & 533 & 57,982 & 55.41 & 3.61 & 9.19 & 55.33 & 3.85 & 9.22 \\
\hline D8 & $3,4,5-\mathrm{OCH}_{3}$ & (R) -Acid & $\mathrm{C}_{35} \mathrm{H}_{28} \mathrm{~N}_{4} \mathrm{O}_{11} \mathrm{~S}_{2}$ & 744.12 & 71 & 500 & 53,583 & 56.32 & 3.90 & 7.49 & 56.45 & 3.79 & 7.52 \\
\hline
\end{tabular}




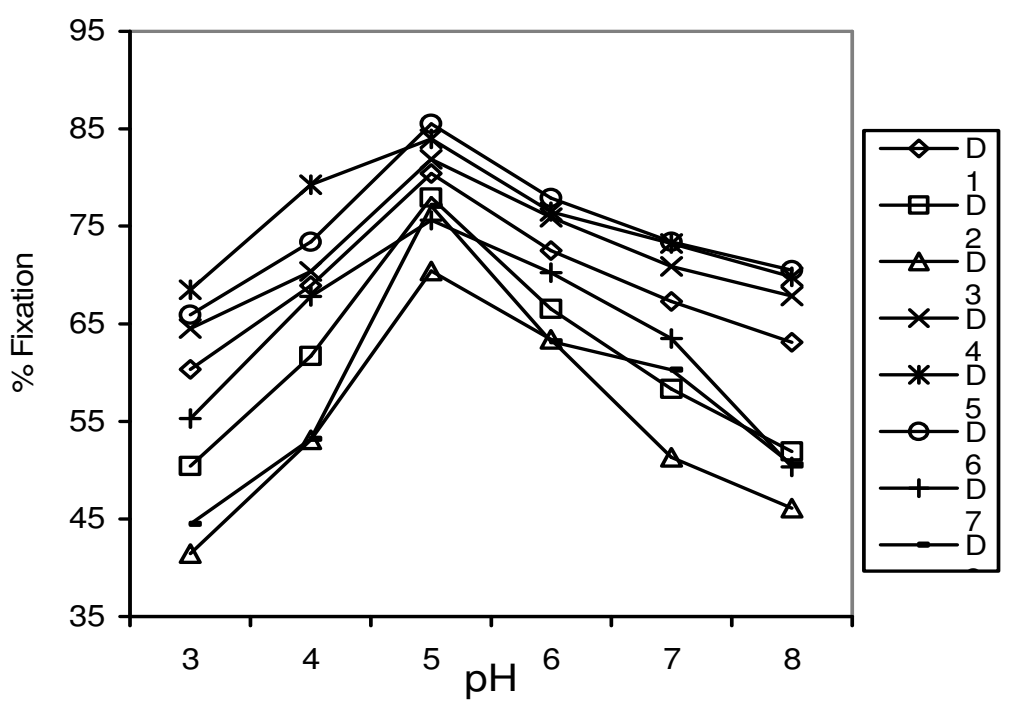

\section{Conclusion}

Figure 6. Effect of application $\mathrm{pH}$ on fixation $(\% \mathrm{~F})$.

This study describes the synthesis of eight novel heterocyclic based monoazo acid dyes using variously substituted imidazol-4one as diazo component and coupled with various aminonaphthol sulphonic acids. Dyes were prepared in good yields and their application on wool and fastness properties were evaluated. These dyes gave mostly orange, light red, brown and purple shades on wool fibers. Spectral properties and effect of $\mathrm{pH}$ on dyeing was successfully demonstrated. Dyeing results on wool and its fastness properties showed encouraging results.

\section{References}

1. Annen O, Egli R, Henzi B, Jakob H and Matzinger P, Rev. Prog. Coloration. 1987, 17,72.

2 Patel K M, Patel V H, Patel M P and Patel R G, Dyes and Pigments, 2002, 55, 53.

3 Towns A D, Dyes and Pigments, 1999, 42, 3.

4 Choi J H, Hong S H and Towns A D, J Soc Dyers Colourists, 1999, 115,32.

5 Choi J H, Hong S H, Lee E J and Towns A D, J Soc Dyers Colourists. 2000, 116,273.

6 Weaver M A and Shuttleworth L, Dyes and Pigments, 1982, 3,81.

7 Trubnikova L I, Journal of Analytical Chemistry, 2001, 56(3),243.

8 Zhanga Y, Zhanga G, Gana Q and Wang S, Dyes and Pigments, 2007, 74(3), 531.

9 Kamel M, Ali M I and Kamel M M, Journal für Praktische Chemie, 2004, 311(2), 219.

10 Efros L S, Kul'bitskii G N and Romanova M G, Chemistry of Heterocyclic Compounds, 1970,6(2), 205.

11 Fadda A A, Etman H A, Amer F A and Barghout, M Journal of Chemical Technology \& Biotechnology. 1995, 62(2),165.

12 Julie K and Stevens G, J Chem Soc., 1981,1,1433.

13 Vogel A I, In: A Text Book of Practical Organic Chemistry; Longman :London, 1971, 909.

14 Bhatt P V, Wadia D N, Patel P M and Patel R M, Asian J Chem., 2006, 18(1), 1248.

15 Vladimir D, Plocek J, Josef K and Andrea N, Dyes and Pigments, 1996, 30(4), 253.

16 Skinner B G and Vickerstaff T, J. Soc. Dyer Colour, 1945, 61,193.

17 Sona Y A, Honga J, Lima H T and Kim T K, Dyes and Pigments, 2005, 66, 231. 


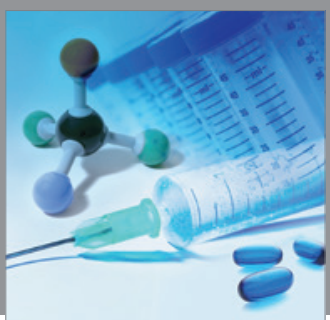

International Journal of

Medicinal Chemistry

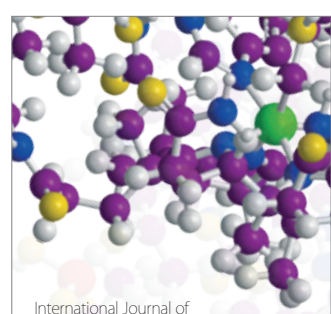

Carbohydrate Chemistry

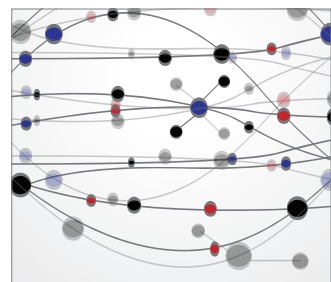

The Scientific World Journal
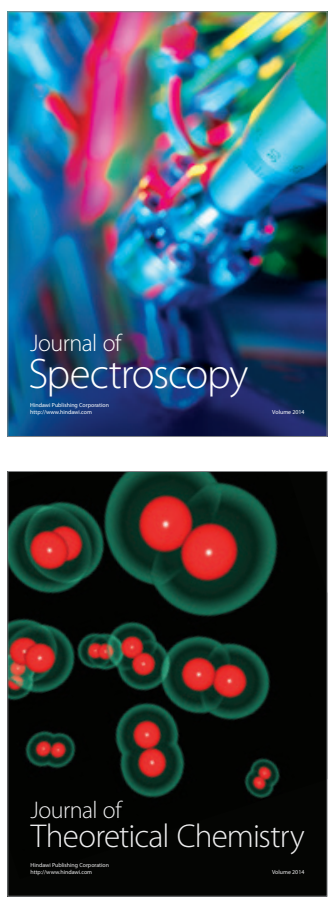
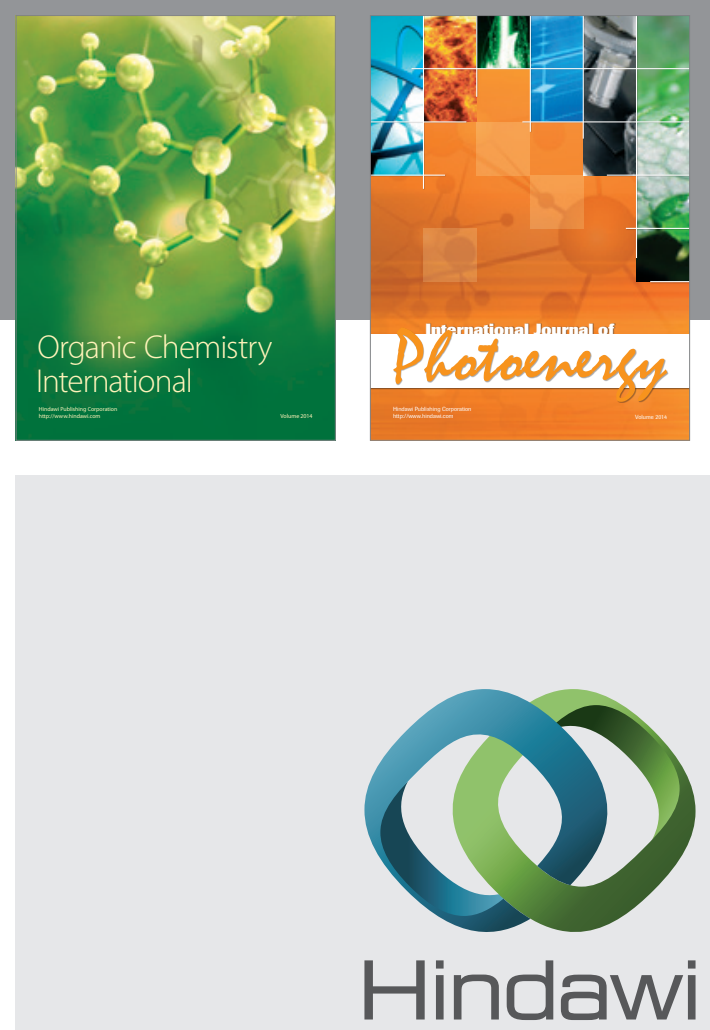

Submit your manuscripts at

http://www.hindawi.com
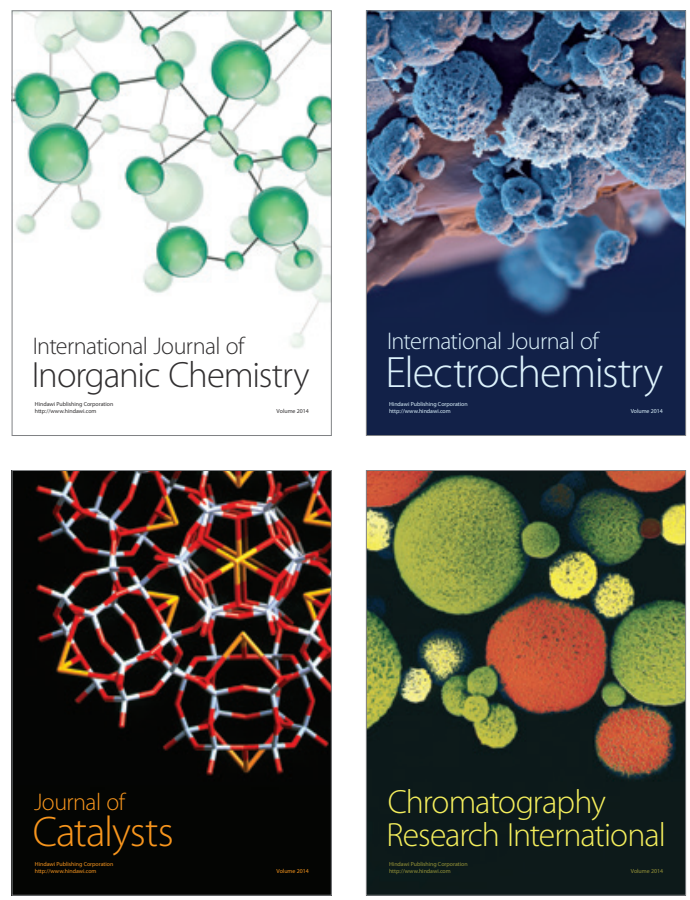
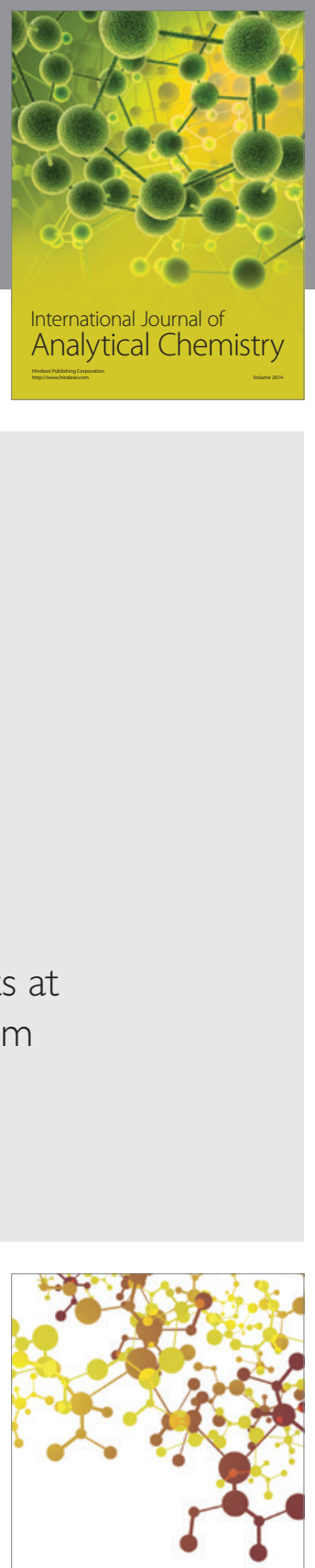

Journal of

Applied Chemistry
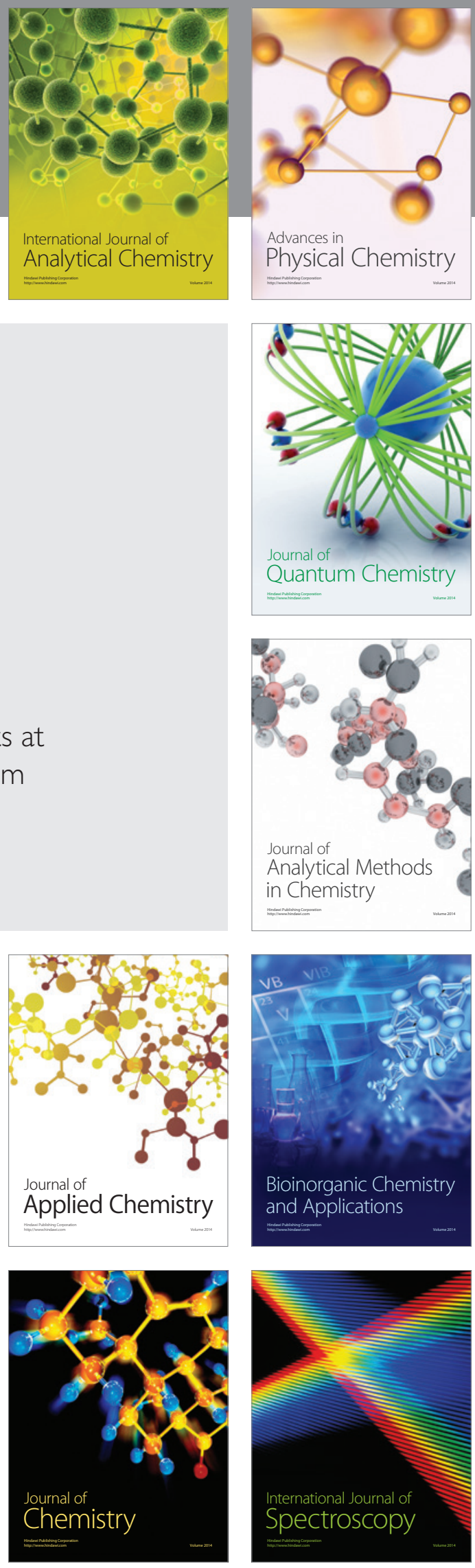